\title{
REPENSANDO NUESTROS ORÍGENES
}

JESÚS ANTONIO DE LA TORRE RANGEL

Departamento de Derecho/UAA

Jesús Gómez Serrano, La guerra chichimeca, la fundación de Aguascalientes y el exterminio de la población aborigen (1548-1620), Un ensayo de reinterpretación, Guadalajara, El Colegio de Jalisco-Ayuntamiento de Aguascalientes, 2001.

\section{Aguascalientes nació en plena gue- rra chichimeca, tanto por el espacio geográfico que ocupa como por la fe- cha de su fundación. La zona en don- de se encuentra Aguascalientes era auténtica tierra de conquista. La re- gión estaba dominada por los chichimecas, entre los cuales desta- caban los cazcanes, los guachichiles, los guamares y los tzacatecos. Indios nómadas y estupendos guerreros. Costó muchas vidas la pacificación de esta zona de la Nueva España, al gra- do de que se afirma que fue en esta}

región donde se puso en auténtico peligro la conquista española.

Powell dedica todo un extenso y documentado libro acerca de la resistencia de los chichimecas, y afirma:

El asombroso triunfo de Cortés creó la ilusión de una superioridad del europeo sobre el indio como guerrero. Pero su relampagueante subyugación de pueblos tan numerosos y complejos como los tlaxcaltecas, aztecas y tarascos no resultó más que un preludio de una mucho más dilatada pugna militar contra las peculiares y aterradoras proezas de los guerreros más primitivos de la América india.

Esta lucha fue llamada -continúa diciendo- la Guerra de los Chichimecas, y empezó casi simultáneamente a la muerte de Hemán Cortés (1547), dando fin, simbólicamente, a la 'primera conquista de México'. La nueva guerra, entablada en las vastas tierras que se extienden al norte de las zonas sojuzgadas por Cortés, 
ensangrentó cuatro décadas, de 1550 a 1590: la guerra contra indígenas más prolongada en toda la historia de Norteamérica...

Fue una nueva clase de guerra, ajena tanto a los europeos cuanto a sus aliados indios, mestizos, negros y mulatos. Los chichimecas tribus y 'naciones' nómadas o seminómadas del norte, tenían una cultura extremadamente primitiva y andaban desnudos; pero eran hombres aterradoramente valerosos, incomparables arqueros y maestros de la guerra de súbitos ataques y retiradas. Hombre por hombre, en sus ancestrales zonas de caza y de guerra, estos combatientes eran muy superiores a sus enemigos que llevaban ropas, y finalmente los chichimecas no fueron vencidos por la fuerza militar. ${ }^{1}$

\section{Ruth Behar, ante la afirmación} de Powell de que el encuentro entre español y chichimeca fue una "cruel confrontación del salvajismo y la civilización", cuestiona: "¿quiénes, en realidad, eran los salvajes?", y agrega:

1 Philip M. Powell, La Guerra Chichimeca (1550-1600), Fondo de Cultura Económica, México, 1977, p. 9.

2 Philip W. Powell, Capitán mestizo: Miguel Caldera y la Frontera Norteña, La Pacificación de los Chichimecas (15481597), Fondo de Cultura Económica, México, 1980, p. 9.
Las percepciones españolas de los chichimecas como gente 'bruta' y 'salvaje' eran en parte una reacción a un encuentro con un pueblo totalmente distinto, un pueblo que vivía de la caza y de la recolección de plantas en vez de la agricultura y la cría de animales: un pueblo cuya independencia y movilidad constituyeron una amenaza peligrosa a la sociedad colonizadora. ${ }^{3}$

Esos lugares denominados por los chichimecas eran paso obligado para los viajeros, que llevaban casi siempre consigo mercaderías y metales, y que iban de una o otra de las ciudades más importantes en aquel entonces de la Nueva España: México, Guadalajara, Zacatecas y Guanajuato; constituyendo por los frecuentes ataques de los indios, constante peligro para sus vidas y haberes, y además, causaban grave perjuicio a la industria minera colonial.

Precisamente tenemos el gusto de comentar el nuevo libro del historiador aguascalentense Jesús Gómez Serrano, que trata los temas que su título refiere, pues el texto se llama:

3 Ruth Behar, Las visiones de una bruja guachichil en 1599: Hacia una perspectiva indígena sobre la conquista de San Luis Potosí, Cuadernos del Centro, El Colegio de San Luis Potosí, San Luis Potosí, 1997, p. 14. 
La guerra chichimeca, la fundación de Aguascalientes y el exterminio de la población aborigen (1548-1620).

El libro es, como el subtítulo lo indica, un ensayo de reinterpretación de estos apasionantes temas que tienen que ver con nuestros orígenes como ciudad; una comunidad que lucha por sobrevivir y al consolidarse ejerce pronto una influencia que rebasa el ámbito de la pequeña villa organizada como municipio a la usanza castellana, al convertirse en sede de Alcaldía Mayor y de Parroquia, a principios del siglo XVII.

Este libro de Gómez Serrano reúne cuanto dato se dispone sobre la fundación de Aguascalientes, ofreciéndonos una nueva síntesis de este hecho histórico y aportando una interpretación novedosa sobre nuestro nacimiento como ciudad, siempre relacionándolo con la Guerra Chichimeca sin lo cual sería inexplicable. Según lo anuncia en el prólogo, el autor se propuso "un trabajo que reuniera toda la información disponible y ofreciera un relato integral, bien documentado y convincente" (p. 9) sobre el tema. Consideramos que logra su propósito y lo hace muy bien.

El libro que comentamos aborda los siguientes temas: los chichimecas, en donde analiza las características de los diversos grupos y su zona de operaciones; toca en concreto el tema de guerra y las diversas etapas por las que pasa; trata de manera amplia lo que es propiamente la fundación de la villa de Aguascalientes; hace un análisis pormenorizado de la cédula de fundación del 22 de octubre de 1575; se refiere al origen y carácter de los fundadores; nos narra los muy difíciles primeros años de la vida de Aguascalientes; toca lo relativo al fin de la guerra; analiza la gran recesión demográfica de la región; se refiere a la creación de la Parroquia y la Alcaldía Mayor; siguiendo las disposiciones del visitador Gaspar de la Fuente, nos habla de la situación de la Villa en 1609; nos describe el nacimiento y consolidación del Pueblo de Indios de San Marcos; y termina ofreciéndonos unas conclusiones destacando lo complejo del proceso histórico relativo al nacimiento, consolidación y crecimiento de Aguascalientes.

Reiteramos: el libro de Gómez Serrano es un estupendo ensayo sobre cómo nace y se forja la comunidad aguascalentense en el tiempo y espacio de la Guerra Chichimeca. En su integridad debe verse y en su integridad es magnífico. Sin embargo queremos destacar algunos rubros 
que nos llamaron especialmente la atención.

El licenciado Gaspar de la Fuente, oidor de la Real Audiencia de Nueva Galicia, como visitador general del propio reino neogallego, realizó a la villa de Aguascalientes una Visita de la tierra en octubre de 1609.

Las Visitas de la tierra constituían una de las jurisdicciones especiales o extraordinarias de las que las Audiencias estaban facultadas. ${ }^{4}$ Tenían como objeto la vigilancia de la aplicación del Derecho de parte de los tribunales inferiores, la inspección del desempeño de las funciones administrativas y el trato que se daba a los indios. Podemos decir que estas Visitas eran un recorrido general de inspección ${ }^{5}$ sobre la buena marcha de los asuntos del lugar visitado; en ellas se informaban y tomaban medidas acerca de la calidad de la tierra, número de pobladores y posibles medios para mejorar su sustento y calidad de

4. Cfr. Oscar Cruz Barney, Historia del Derecho en México, Ed. Oxford, México, 1999, p. 272.

5 Cfr. José Encino Contreras, "Las Ordenanzas de la Audiencia de la Nueva Galicia", en Quid Iustitia, Revista del Tribunal Superior de Justicia del Estado de Zacatecas, no. 1, junio de 1994, p. 18. vida en general. ${ }^{6}$ La Visita de Gaspar de la Fuente a la villa de Aguascalientes, se adapta al fin de esta institución, de tal modo que, una vez inspeccionada la ciudad de las aguas termales y analizando integralmente su estado, le permiten al oidor emitir mandamientos urbanos, así como al uso de la tierra, agua y ganado.

Gómez Serrano da a conocer el contenido y analiza el acta levantada con motivo de la Visita, de 25 de octubre de 1609, y así puede describirnos la situación de Aguascalientes en ese año. Creo que el autor lleva razón al decir que se trata de "una verdadera acta de refundación de la villa", en virtud de la normatividad que, en materia urbana y para la mejor convivencia de los vecinos, es dictada por el oidor-visitador.

En otro lugar, Gómez Serrano hace un magnífico tratamiento de cómo se forma y es reconocido jurídicamente el Pueblo de Indios de San Marcos. Creo que resuelve la controversia entre aquellos que hemos sostenido

6 Cfr. Antonio Dougnac Rodríguez, Manual de Historia del Derecho Indiano, Ed. Universidad Nacional Autónoma de México, México, 1994, p. 161; y Cruz Barney, ob. cit., p. 283. 
que San Marcos tuvo fundación legal desde su origen y que se trataba de un grupo étnico homogéneo ${ }^{7}$ y aquellos otros que han sostenido que "no es posible reconocer a San Marcos como pueblo jurídicamente establecido y con las prerrogativas que encerraban las leyes españolas". El autor sostiene que de forma no planeada, de tratarse de un caserío de indios de distintas procedencias, San Marcos parece haber evolucionado a "república" de naturales, con sus propias autoridades y reconocimiento explícito e implícito como Pueblo de Indios por las autoridades novohispanas, con los consecuentes derechos que de tal calidad derivan.

El autor también pone de relieve la importancia que tuvo para el desarrollo de Aguascalientes la erección

7 Cfr. Alejandro Topete del Valle, Aguascalientes. Guía para visitar la Ciudad y el Estado, Ed. del autor. Aguascalientes, 1973, p. 68; y Jesús Antonio de la Torre Rangel, Notas Histórico-Jurídicas sobre la Fundación de Aguascalientes, Ed. del autor, México, 1990, págs. 85-95.

José Antonio Gutiérrez Gutiérrez, Historia de la Iglesia Católica en Aguascalientes, Ed. Universidad Autónoma de Aguascalientes, Obispado de Aguascalientes y Universidad de Guadalajara, 1999, p. 124. de la parroquia de la Asunción y la creación de una alcaldía mayor con sede en la villa de Aguascalientes; y nos trasmite sus reflexiones muy interesantes sobre estos hechos.

Además, el doctor Gómez Serrano nos ofrece un análisis detallado y muy interesante de la cédula de fundación de Aguascalientes de 22 de octubre de 1575. Considera que este fundamental documento consta de tres partes constitutivas. La primera es un recuento de los hechos y las gestiones realizadas por Juan de Montoro para fundar y poblar la villa de Aguascalientes, el lugar en donde lo hizo y los motivos para ello. En la segunda parte, viene la resolución atribuida al rey, tomada por la audiencia de Nueva Galicia en su nombre y representación, de otorgar una merced de tierras y autorización para fundar en las mismas la villa de Aguascalientes. Y en la tercera parte, se sanciona jurídicamente la fundación, se determina la pública utilidad de la misma y se precisan las prerrogativas de las cuales gozará.

Sin embargo, en este punto del análisis de la cédula de 22 de octubre de 1575, mi amigo Jesús Gómez es injusto al decir, refiriéndose a mi texto sobre la fundación de Aguascalientes: “De la Torre [...] no 
entra al análisis de la naturaleza jurídica del documento" (p. 49).

Sin demeritar, de ningún modo, el libro que comento, debo hacer uso de la legítima defensa propia. En el capítulo V de mis Notas Histórico-Jurídicas sobre la Fundación de Aguascalientes, titulado "Los Fueros Municipales" hago el análisis jurídico de la cédula de fundación de Aguascalientes, y concluyo, como lo hace Jesús Gómez, en el sentido de que se trata de una merced de la Corona otorgada a particulares para fundar la villa en el territorio de la Nueva Galicia (p. 50). Sólo que, por mi formación de jurista, trato de profundizar en el tema. Entre otras cosas escribí en ese lugar:

La Real Cédula de fundación de la ciudad de Aguascalientes expedida por Jerónimo de Orozco, en representación de Felipe II, constituye, en sentido amplio, un fuero municipal, de la especie denominada "carta puebla".

Fueros Municipales, en términos generales se les denomina a todos los documentos dados para regular, auque fuese de manera muy general, la vida colectiva de las distintas localidades. Estos fueros municipales en sentido amplio, se dividían en dos tipos distintos de ellos: "fueros municipales" en sentido estricto y "cartas pueblas" o "cartas de población". Los primeros constituyen una ley para una población ya formada; mientras que las "cartas pueblas" tienen como fin princi- pal la población del territorio, y para atraer pobladores se ofrece a los que allí se establezcan determinadas ventajas, como son exenciones de tributos, tierras, casas y aprovechamientos en montes y prados. ${ }^{9}$

Se explica más adelante que las "cartas puebla" implican merced de tierras, como lo fue el caso de la villa de Aguascalientes.

Fueros municipales y cartas de población eran otorgados por la autoridad real cuando se trataba de territorios de realengo, es decir, de tierras que entraban en el tesoro real, que era patrimonio de la Corona, destinadas a la administración, orden y defensa del Reino. Caso en el cual se encontraban las tierras de la Nueva España. ${ }^{10}$

Para terminar este comentario quisiera resaltar el interesante análisis que hace Gómez Serrano del "casi total exterminio de la población aborigen", en buena medida debido a la situación de gúerra. En su momento, el autor hace referencia a la polémica que la propia contienda generó, en la que se da la discusión sobre cuestiones de justicia e injusticia con relación a la misma; es el planteamiento

9 Jesús Antonio de la Torre, Ob. cit., págs. 43 y 44, ed. 1982; p. 61, ed. 1990.

10 Idem, supra. 
ético de la legitimidad de la guerra "a sangre y fuego" como se decía y de la posibilidad de hacer esclavos a los indios cautivos en esa guerra. En el fondo es un debate sobre los derechos de los indios. Al analizar la Guerra Chichimeca, Alberto Carrillo Cázares dice que el intento de acabar con los indios "no es un proyecto recientemente maquinado, es un problema original de este país"; ${ }^{11}$ es cierto, pero también desde los orígenes de México se han defendido sus derechos. Esto es sólo una muestra del complejo nacimiento de nuestra patria.

Pues bien, La guerra chichimeca, la fundación de Aguascalientes y el exterminio de la población aborigen (1548-1620) de Jesús Gómez Serrano es un estudio del cual se desprenden diversos aspectos de la enorme complejidad cómo la Nueva España se fue forjando, distintos hilos con los que México se fue tejiendo. Su lectura nos ayuda a entender en buena medida a México y, con mucha mayor razón, a Aguascalientes y su región.
6)

11 Alberto Carrillo Cázares, El debate sobre la Guerra Chichimeca. Derecho y política en la Nueva España, Vol I. Ed. El Colegio de Michoacán y El Colegio de San Luis, 2000 , p. 35. 
